\title{
Optogenetic Evidence That Pallidal Projections, Not Nigral Projections, from the Nucleus Accumbens Core Are Necessary for Reinstating Cocaine Seeking
}

\author{
Michael T. Stefanik, Yonatan M. Kupchik, Robyn M. Brown, and Peter W. Kalivas \\ Department of Neuroscience, Medical University of South Carolina, Charleston, South Carolina 29425
}

The core subcompartment of the nucleus accumbens (NAcore) contributes significantly to behavioral responses following motivationally relevant stimuli, including drug-induced, stress-induced, and cue-induced reinstatement of cocaine seeking. Projections from NAcore that could carry information necessary to initiate reinstated cocaine seeking include outputs via the indirect pathway to the dorsolateral subcompartment of the ventral pallidum (dlVP) and through the direct pathway to the medial substantia nigra (SN). Here we used an optogenetic strategy to determine whether the dlVP or nigral projections from the NAcore are necessary for cocaine seeking initiated by a cocaine and conditioned cue combination in rats extinguished from cocaine self-administration. Rats were pretreated in the NAcore with an adeno-associated virus expressing the inhibitory opsin archaerhodopsin, and fiber-optic cannulae were implanted above the indirect pathway axon terminal field in the dIVP, or the direct pathway terminal field in the SN. Inhibiting the indirect pathway to the dlVP, but not the direct pathway to the $\mathrm{SN}$, prevented cocaine-plus-cue-induced reinstatement. We also examined projections back to the NAcore from the ventral tegmental area (VTA) and dlVP. Inhibiting the dlVP to NAcore projection did not alter, while inhibiting VTA afferents abolished reinstated cocaine seeking. Localization of green fluorescent protein reporter expression and whole-cell patch electrophysiology were used to verify opsin expression. These data reveal a circuit involving activation of VTA inputs to the NAcore and NAcore projections through the indirect pathway to the dIVP as critical for cocaine-plus-cue-induced reinstatement of cocaine seeking.

\section{Introduction}

Cocaine addiction is a disorder characterized by chronic relapses stemming from maladaptive behaviors that lead to drug consumption, often with grave personal and social consequences. Studies with cocaine addicts reveal marked changes in the structure and activity of brain circuits regulating reward and cognition (Ersche et al., 2011; Goldstein and Volkow, 2011). Similar results are seen in animal models of relapse, including neuroadaptations in the nucleus accumbens and the circuitry in which the accumbens is embedded (Wolf, 2010). The accumbens has a major physiological role in integrating and translating environmental stimuli into motivated behaviors (Koob and Volkow, 2010), and undergoes a number of enduring cocaine-induced cellular adaptations thought to contribute to the vulnerability to relapse, including changes in excitatory regulation of medium spiny neurons (MSNs; Kalivas, 2009; Wolf, 2010; Lüscher and Malenka, 2011).

Recently, we used an optogenetic strategy using adenoassociated virus (AAV) delivery of the inhibitory opsin archaer-

\footnotetext{
Received April 11, 2013; revised July 6, 2013; accepted July 10, 2013.

Author contributions: M.T.S. and P.W.K. designed research; M.T.S., Y.M.K., and R.M.B. performed research; M.T.S., Y.M.K., and P.W.K. analyzed data; M.T.S. and P.W.K. wrote the paper.

This work was supported by National Institutes of Health T32 DA7288 and Grants DA015369, DA012513, and DA003906 (P.W.K.).

The authors declare no competing financial interests.

Correspondence should be addressed to Peter Kalivas, PhD, Medical University of South Carolina, 173 Ashley Avenue, BSB 403, Charleston, SC 29425. E-mail: kalivasp@musc.edu.

DOI:10.1523/JNEUROSCI.1570-13.2013

Copyright $\odot 2013$ the authors $\quad 0270-6474 / 13 / 3313654-09 \$ 15.00 / 0$
}

hodopsin (ArchT) in the reinstatement animal model of cocaine relapse, to show that inhibiting prelimbic prefrontal cortex (PL) glutamatergic input to the core subcompartment of the nucleus accumbens (NAcore) prevents reinstated cocaine seeking (Stefanik et al., 2013). Here we use the same approach to determine the role of projections from the NAcore in reinstated cocaine seeking. Output from the NAcore consists of two populations of MSNs based on whether they contribute to the direct projection to the medial substantia nigra ( $\mathrm{SN}$ ) or the indirect projection to the dorsolateral ventral pallidum (dlVP; Heimer et al., 1991; Gerfen and Surmeier, 2011; Lobo and Nestler, 2011; Smith et al., 2013). MSNs are also divided into two populations according to their selective expression of dopamine receptors. While D1expressing MSNs comprise the direct pathway, the indirect projection to the dlVP contains afferents from both D1-expressing and D2-expressing MSNs (Lu et al., 1998; Smith et al., 2013). Using cell-type selective opsin expression, activation of D1expressing MSNs in the accumbens potentiates reward, while D2 activation inhibits reward (Lobo et al., 2010; Kravitz et al., 2012). The brain circuitry underlying cocaine reward and the development of cocaine-seeking behavior is partly distinct from relapse (reinstated cocaine seeking; Kalivas and Volkow, 2005; Koob and Volkow, 2010; Lüscher and Malenka, 2011). Therefore, we designed experiments to examine the relative contributions of direct NAcore projections to the medial SN and indirect projections to the dlVP in reinstated cocaine seeking. We also evaluated involvement of the reciprocal GABAergic projection from the dlVP back to the NAcore (Hakan et al., 1992; Churchill and Ka- 
livas, 1994), and the mixed dopamine/glutamate/GABA projection from the ventral tegmental area (VTA) to the NAcore (Stuber et al., 2010; Brown et al., 2012; van Zessen et al., 2012). From these experiments, we conclude that activity in a circuit containing projections from the PL and VTA to the NAcore and from the NAcore to the dlVP is necessary for reinstated cocaine seeking.

\section{Materials and Methods}

Animal housing and surgery. Male Sprague Dawley rats (250-300 g; Charles River Laboratories) were single housed in a facility accredited by the Association for the Assessment and Accreditation of Laboratory and Animal Care. The animals were kept under temperature-controlled and humidity-controlled conditions with a $12 \mathrm{~h}$ reverse light/dark cycle (lights on at 6:00 P.M.). Rats were fed ad libitum until $7 \mathrm{~d}$ postsurgery, after which food was restricted to four chow pellets per day. Water was always available ad libitum. All methods used were in compliance with the National Institutes of Health Guide for the Care and Use of Laboratory Animals and were approved by the Medical University of South Carolina Institutional Animal Care and Use Committee.

Surgery followed 1 week of acclimation and handling. Rats underwent surgeries for injection of AAV, implantation of cannulae, and implantation of indwelling jugular catheters under ketamine $\mathrm{HCl}(87.5 \mathrm{mg} / \mathrm{kg}$ Ketaset, Fort Dodge Animal Health) and xylazine (2 mg/ml Rompum, Bayer) anesthesia. For virus microinjections, $0.7 \mu \mathrm{l}$ of virus (rAAV2CAG-ArchT-GFP or rAAV5-CMV-GFP, $\sim 10^{12}$ viral particles/ml; University of North Carolina Vector Core) was delivered bilaterally through a 33 ga needle $(0.14 \mu \mathrm{l} / \mathrm{min}$ for $5 \mathrm{~min})$. This construct was chosen for its increased photocurrents relative to light-driven chloride pumps (such as halorhodopsin) as well as for the ability to recover completely following light cessation (Chow et al., 2010). The needles were left in place for 10 min following injection to allow for diffusion away from the injection site, and then slowly retracted. For viral microinjections, the coordinates from bregma were as follows: NAcore: $+1.5 \mathrm{~mm}$ anteroposterior, $\pm 3.0 \mathrm{~mm}$ mediolateral, $-6.5 \mathrm{~mm}$ dorsoventral from skull surface ( $9^{\circ}$ angle); dlVP: $-0.1 \mathrm{~mm}$ anteroposterior, $\pm 3.5 \mathrm{~mm}$ mediolateral, $-8.2 \mathrm{~mm}$ dorsoventral $\left(10^{\circ}\right.$ angle $)$; VTA: $-5.4 \mathrm{~mm}$ anteroposterior, $\pm 2.2 \mathrm{~mm}$ mediolateral, $-9.1 \mathrm{~mm}$ dorsoventral ( $10^{\circ}$ angle); $\mathrm{SN},-5.4 \mathrm{~mm}$ anteroposterior, $\pm 2.4 \mathrm{~mm}$ mediolateral, $-8.1 \mathrm{~mm}$ dorsoventral ( $10^{\circ}$ angle $)$.

Intrajugular catheters were implanted, as previously described (LaLumiere et al., 2012). Catheters were flushed daily with cefazolin $(0.2$ $\mathrm{ml}$ of $0.1 \mathrm{~g} / \mathrm{ml})$ and heparin $(0.2 \mathrm{ml}$ of $100 \mathrm{IU})$ for 1 week, then daily with heparin for the remainder of the experiment to prevent infection and maintain catheter patency. Guide cannulae (20 ga; Plastics One) for retractable optic fibers or chronically implantable optic fibers (Precision Fiber) were implanted $0.5 \mathrm{~mm}$ dorsal to the site intended to receive light stimulation (Sparta et al., 2012). Cannulae or chronic fibers were secured to the skull with small screws and dental acrylic, obdurators were inserted to prevent obstruction of the cannulae, and animals recovered for 1 week before behavioral training.

Self-administration, extinction, and reinstatement procedures. All training was conducted in standard operant chambers equipped with two retractable levers, a house light, cue light, and tone generator $(2900 \mathrm{~Hz}$; Med Associates). Food was removed for $24 \mathrm{~h}$ and then a single $15 \mathrm{~h}$ food training session was conducted where rats were trained to press the active lever for a single food pellet (45 mg; Noyes) on a fixed-ratio 1 (FR1) schedule. On the following day, animals began $2 \mathrm{~h}$ sessions of cocaine self-administration using an FR1 schedule with a $20 \mathrm{~s}$ time out. Active lever presses resulted in a $0.05 \mathrm{ml}$ infusion of $200 \mu \mathrm{g}$ cocaine (dissolved in $0.9 \%$ sterile saline; National Institute on Drug Abuse) and the concurrent illumination of the stimulus light above the lever with a $2900 \mathrm{~Hz}$ tone for $5 \mathrm{~s}$. Inactive lever presses were of no programmed consequence. Rats underwent self-administration $6 \mathrm{~d} /$ week for at least 2 weeks (a minimum of 12 sessions), until they met the maintenance criteria of $\geq 10$ infusions of cocaine over $10 \mathrm{~d}$, including the last $3 \mathrm{~d}$ of self-administration, as well as discrimination between the active and inactive levers $(>75 \%$ lever presses on active lever). Rats not reaching these criteria after 4 weeks were excluded from the study.

Extinction training $(2 \mathrm{~h} / \mathrm{d})$ began following the successful acquisition of cocaine self-administration. During extinction, active lever presses never resulted in a drug infusion or light/tone cue. All rats underwent at least $10 \mathrm{~d}$ of extinction, until active lever-pressing fell to $<30 \%$ of the average responding during self-administration. For insertable fibers, optical manipulations required attaching a leash to the guide cannulae. Rats were habituated to the leash in three extinction sessions before reinstatement testing in which obdurators were removed and leashes attached for $2 \mathrm{~h}$ before as well as during the $2 \mathrm{~h}$ extinction session. For chronically implantable fibers, animals were habituated to the fibers for $\geq 3$ sessions during extinction training. Immediately before testing, the fibers were attached and remained in place for the duration of the $2 \mathrm{~h}$ reinstatement session. Rats then underwent cocaine-plus-cue-primed reinstatement where they received a single injection of cocaine $(10 \mathrm{mg} / \mathrm{kg}$, i.p.) immediately before the session. During the reinstatement sessions, active lever presses produced the light/tone cues that had been present during selfadministration, but no cocaine was delivered. All animals underwent two reinstatement sessions, counterbalanced with respect to whether illumination was given.

Open-field locomotor activity. Following the completion of reinstatement testing, animals underwent open-field testing to examine the effects of optical illumination on locomotor activity. Activity was monitored in clear Plexiglas boxes by a series of 16 photobeams measuring horizontal activity. Beam breaks were counted and recorded by a computer running Digiscan software (AccuScan Instruments). Optic fibers were connected, animals were administered a $15 \mathrm{mg} / \mathrm{kg}$ intraperitoneal cocaine injection, and either sham or laser illumination was counterbalanced over the $60 \mathrm{~min}$ measurement periods after the animal was placed into the box.

Optical inhibition. The optical probes consisted of a $200 \mu \mathrm{m}$ optic fiber (multimode, 0.37 numerical apeture) that was inserted and epoxied into a 24 ga internal cannula, which extended $1 \mathrm{~mm}$ beyond the guide cannula, or a chronically implantable optic fiber housed in a stainless steel ferrule. For insertable probes, the fiber extended $0.5 \mathrm{~mm}$ beyond the end of the internal cannula, thus terminating $\sim 0.5 \mathrm{~mm}$ dorsal to the site intended to receive light. During testing, the probe was inserted into the guide and secured to the head through a metal leash attached to the guide. For chronically implantable fibers, the fiber terminated $0.5 \mathrm{~mm}$ dorsal to the target site. To permit simultaneous, bilateral illumination, the other end of the optic fiber (FC/PC connection) was attached to a $2 \times$ 1 fiber splitter (Fibersense or Precision Fiber, respectively). The single end of the splitter was attached to a rotating optical commutator to relieve torque and permit ad libitum movement by the animal. The commutator was connected via a fiber to a laser (diode-pumped solid-state, $200 \mathrm{~mW}, 561 \mathrm{~nm}$, multimode FC/PC fiber coupler connection; OEM Laser Systems). Light output was measured with an optical power meter and adjusted to $\sim 10 \mathrm{~mW}$ of $561 \mathrm{~nm}$ light. Based on in vivo measurements of light output in mammalian brain tissue, these parameters would be expected to provide sufficient light for opsin activation in at least 0.4 $\mathrm{mm}^{3}$ of tissue (Yizhar et al., 2011). Light was applied continuously for the $2 \mathrm{~h}$ reinstatement or locomotor activity session. Continuous light delivery protocols (10 and 15 min duration) in ArchT-expressing neurons have previously been shown to inhibit neuron firing without desensitizing, and firing returned to baseline immediately after the light was turned off (Huff et al., 2013; Tsunematsu et al., 2013). Using whole-cell patch recordings of ArchT-infected MSNs in NAcore, we also found that continuous light caused stable membrane hyperpolarization for $20 \mathrm{~min}$, and when the light was extinguished the membrane potential immediately rose to baseline (M.T. Stefanik and Y.M Kupchik, unpublished observations).

Immunohistochemistry and imaging. Rats were anesthetized with pentobarbital $(100 \mathrm{mg} / \mathrm{ml}$, i.p.) and then transcardially perfused with PBS, pH 7.4, followed by PBS containing 4\% (w/v) paraformaldehyde. Brains were postfixed for $24 \mathrm{~h}$ at room temperature in the perfusion solution. Coronal sections ( $50 \mu \mathrm{m}$ thick) were incubated for $60 \mathrm{~min}$ in $1 \%$ hydrogen peroxide, rinsed three times in PBS, and then incubated overnight in PBS containing $0.25 \%$ Triton $\mathrm{X}, 0.01 \%$ sodium azide, and anti-GFP 
(rabbit, 1:50,000; Abcam) antibody. Sections were then rinsed once in PBS and incubated for 30 min in PBS containing the biotinylated secondary antibody (donkey, 1:1000; Jackson Immunoresearch) for $30 \mathrm{~min}$, rinsed four times in $\mathrm{PBS}$, and incubated for $1 \mathrm{~h}$ in an ABC Kit (Vector Labs). Sections were then rinsed once in PBS and incubated in PBS with $0.05 \%$ diaminobenzidine with $0.05 \%$ hydrogen peroxide for $\sim 5 \mathrm{~min}$. Slices were then mounted and ArchT expression was visualized on a light microscope. For observation of native fluorescence, the GFP tag was excited using a helium/ neon $543 \mathrm{~nm}$ laser line with a GFP excitation filter on a Leica confocal microscope. Images were scanned at a system-optimized thickness along the $z$-axis, and the frame size for images was set at $1024 \times 1024$ pixels.

Slice preparation and electrophysiological recordings. Separate cohorts of rats were prepared specifically for use in electrophysiological recordings. These rats were anesthetized with ketamine $\mathrm{HCl}(100 \mathrm{mg} / \mathrm{kg})$ and decapitated. The brain was removed and sagittal slices $(220 \mu \mathrm{m})$ were prepared (VT1200S Leica Vibratome, Leica Microsystems) and collected into a vial containing aCSF [(in mM) 126 sodium chloride, 1.4 sodium phosphate, 25 sodium bicarbonate, 11 glucose, 1.2 magnesium chloride, $2.4 \mathrm{cal}-$ cium chloride, 2.5 potassium chloride, 2.0 sodium pyruvate, 0.4 ascorbic acid, bubbled with $95 \%$ oxygen and $5 \%$ carbon dioxide] and a mixture of $5 \mathrm{~mm}$ kynurenic acid and $100 \mu \mathrm{M}$ MK-801 maleate. Slices were stored at room temperature until used. All recordings were made at $32^{\circ} \mathrm{C}$ (TC-344B, Warner Instrument) and in the presence of $10 \mu \mathrm{M} C N Q X$. Neurons were visualized with an Olympus BX51WI microscope. Multiclamp 700B (Molecular Devices) was used to record IPSCs under $-80 \mathrm{mV}$ voltage-clamp whole-cell configuration. Glass microelectrodes (1-2 M $\Omega$ ) were filled with internal solution containing (in $\mathrm{mm}$ ) the following: 68 potassium chloride, $65 \mathrm{D}$-gluconic acid potassium salt, 7.5 HEPES potassium, 1 EGTA, $1.25 \mathrm{MgCl}_{2}, 10 \mathrm{NaCl}, 2.0$ MgATP, and 0.4 NaGTP, pH 7.2-7.3, 275 mOsm. YFP fluorescence was induced using an X-Cite 120 PC fluorescent lamp (Lumen Dynamic Group) to verify injection site (ventral pallidum or NAcore) before patching a cell. After patching a cell, the optic fiber was positioned in the vicinity of the recorded cell. Recorded neurons were shown to be not infected by ArchT by delivering a laser pulse $(561 \mathrm{~nm})$ in the currentclamp mode. None of the recorded cells showed a change in the resting membrane potential during this laser pulse (data not shown). To measure the effect of the laser pulse on evoked IPSCs, an electrical stimulation was delivered using a bipolar electrode (FHC) every $30 \mathrm{~s}$ and the laser pulse was delivered every other stimulation. The bipolar stimulating electrode was placed $\sim 200-300 \mu \mathrm{m}$ rostral of the recorded cell in the ventral pallidum or $\mathrm{SN}$, or caudal to the NAcore. The stimulation intensity was set to evoke $\sim 50 \%$ of maximal IPSC. Laser pulse was $500 \mathrm{~ms}$ in duration and started $300 \mathrm{~ms}$ before the electrical pulse was delivered. For spontaneous IPSCs (sIPSCs) recordings were continuous with a $4 \mathrm{~s}$ laser pulse applied every 6 s. sIPSCs during the laser pulse were compared with the sIPSCs in the $4 \mathrm{~s}$ before each laser pulse. Data were acquired at $10 \mathrm{kHz}$, and filtered at $2 \mathrm{kHz}$ using AxoGraph X software (AxoGraph Scientific). Series resistance (Rs), measured with a $2 \mathrm{mV}$ depolarizing step (10 ms) given with each stimulus, and holding current were always monitored online. Recordings with unstable Rs, or when Rs exceeded $10 \mathrm{M} \Omega$, were aborted.

Data analysis. A Kolmogorov-Smirnov test revealed that some of the reinstatement data were not normally distributed. Therefore a Friedman repeated-measures nonparametric test was used followed by a Dunn's post hoc analysis for multiple comparisons. Locomotor data were evaluated using a paired-sample Student's $t$ test. Data were analyzed in Prism
(GraphPad Software). Statistical significance was set at $p \leq 0.05$, and data are presented as mean \pm SEM.

\section{Results}

Optical inhibition of the indirect pathway

To assess necessary involvement of activity in the indirect pathway from the NAcore to the dlVP in cocaine-plus-cue-induced reinstated cocaine seeking, an AAV expressing the light-activated inhibitory proton pump archaerhodopsin (AAV-ArchT; Chow et al., 2010) was microinjected into the NAcore and optic fibers were inserted into the dlVP. Importantly, while the ventral pallidum contains both direct pathway neurons projecting out of the basal ganglia to the mediodorsal thalamus (Churchill et al., 1996) and indirect pathway ventral pallidal neurons projecting within the basal ganglia to the subthalamic nucleus and SN (Zahm, 1989; Bell et al., 1995), the neurons projecting to the mediodorsal thalamus are overwhelmingly located in the ventromedial ventral pallidum. Thus, the dlVP contains almost exclusively the indirect pathway projecting ventral pallidum cells (Churchill et al., 1996; Smith et al., 2013). By limiting fiber implantation to the dlVP, we targeted the indirect projection from NAcore MSNs (see Fig. $5 \mathrm{~A}$, cannula placements in dlVP).

Following self-administration and extinction training (Fig. $1 A$ ), animals underwent a cocaine-plus-cue-primed reinstatement in the presence or absence of $\sim 10 \mathrm{~mW}$ of $561 \mathrm{~nm}$ light in the dlVP using a counterbalanced, within-subjects design. Rats microinjected with control AAV-GFP were treated identically, except that they were injected with a virus that coded only for GFP expression. Figure $1 B$ shows that the AAV-ArchT injection site typically included both the NAcore and ventromedial striatum. However the location of the optic fiber in the dlVP allowed selective stimulation of NAcore indirect projection since neither the medial striatum nor shell subcompartment of the accumbens (NAshell) strongly innervate this pallidal subregion (Heimer et al., 1991). Figure $1 C$ shows an example of the dense network of fibers in the dlVP containing GFP immune-staining following 

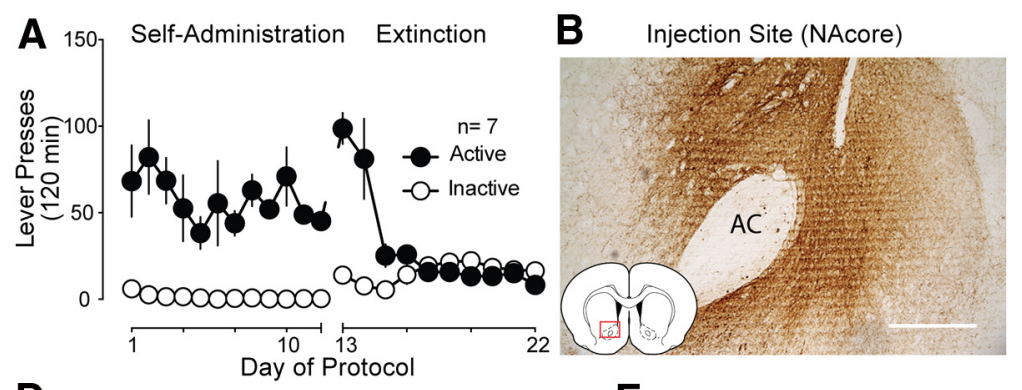

E

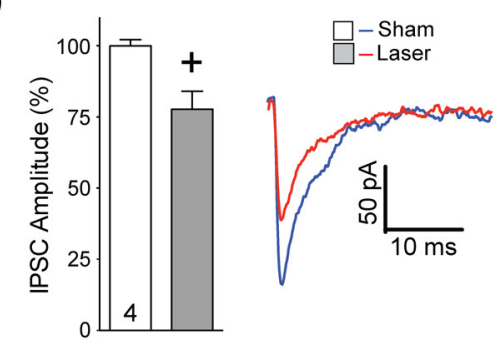

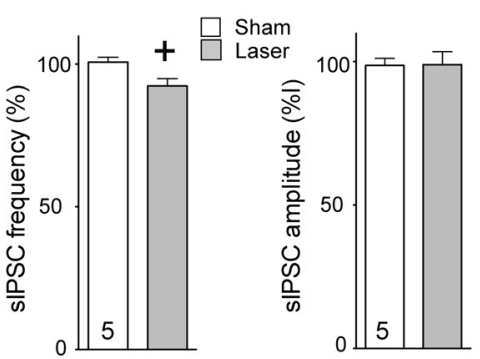
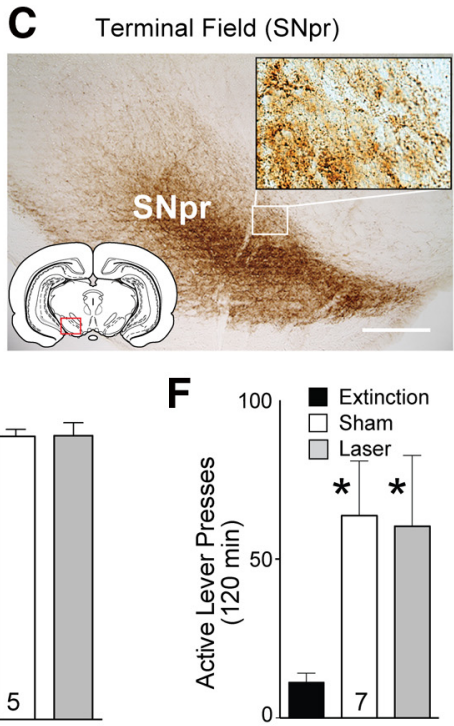

Figure 2. Inhibition of NAcore terminals in the SN fails to block cocaine-plus-cue-primed reinstatement. $A$, Active lever-pressing during self-administration and extinction training for this group of rats $(n=7)$. $\boldsymbol{B}$, GFP expression in NAcore after ArchT-GFP injection into the NAcore. $\boldsymbol{C}$, ArchT-GFP expression in fibers in the SN after virus injection in the NAcore. High-magnification insert shows immunoreactive puncta, indicative of axon terminals. D, Evoked IPSC amplitude measured in SN reticulata neurons was reduced by activating ArchT-expressing fibers labeled via virus injection in the NAcore (left, mean \pm SEM; right, representative IPSCS). $\boldsymbol{E}$, Spontaneous IPSC frequency was reduced by inhibiting ventral pallidum fibers into the NAcore, ${ }^{+} p<0.05$ comparing laser to sham without changing amplitude. $\boldsymbol{F}$, Inactivation of ArchT-expressing NAcore fibers in the SN failed to suppress cocaine-plus-cue-primed reinstatement. $n$ shown in bars. AC, Anterior commissure. Scale bar, $300 \mu \mathrm{m} .{ }^{*} p<0.05$ compared with extinction levels of active lever-pressing.

AAV-ArchT-GFP administration into the NAcore, and the highmagnification insert shows that much of the immune-staining was concentrated in puncta indicative of synaptic terminations. Whole-cell patch recordings from rats infected with AAVArchT-GFP in the NAcore revealed that light activation of ArchT-expressing fibers in the NAcore afferents significantly reduced evoked IPSCs measured in dlVP neurons (Fig. 1D; Wilcoxon $p=0.002$ ). The lack of complete inhibition of electrically stimulated IPSCs reflects the presence of significant uninfected GABAergic axon terminations in the dlVP. These inputs could be insufficiently infected MSN efferents from the accumbens, such as the dense dlVP innervation by the accumbens rostral pole (Zahm and Heimer, 1993), or from dlVP interneurons or nearby GABAergic projection neurons providing lateral inhibition (Kupchik and Kalivas, 2013). Despite not being able to optogenetically inhibit all GABAergic input to the dlVP, Figure $1 E$ shows a significant reduction in active lever-pressing produced by optical inhibition compared with sham treatment (Friedman statistic, 16.55, $p<0.001$ ). Importantly, lever-pressing in the presence of optogenetic inhibition was not statistically different from extinction lever-pressing, supporting a critical role for NAcore GABAergic projections to the dlVP in reinstated lever-pressing. Reinstated lever-pressing was greater than extinction lever-pressing and equivalent between the light and sham treatment in animals infected with the control AAV-GFP (Fig. 1E; Friedman statistic, 6.50, $p=0.042$ ). To control for nonspecific effects on motor behavior, we showed that optical inhibition had no effect on cocaine-induced locomotion (Fig. $1 F$; paired $t_{(11)}=$ $1.78, p=0.103)$.

\section{Optical inhibition of the direct pathway}

The NAcore also has a major projection to the medial SN, referred to as the direct pathway (Owesson-White et al., 2009; Watabe-Uchida et al., 2012). Figure 2 shows that inhibiting the direct projection from the NAcore to the SN did not reduce reinstated cocaine seeking. Figure $2 A$ illustrates the self- administration and extinction data for the group of animals used to study the direct projection. Figure $2 B, C$ shows examples of immune-staining for ArchT-GFP, indicating the location of AAV-ArchT-GFP infection in the NAcore and the location of densely expressed ArchT-GFP in fibers in the medial SN. The insert shows that most of the immune-staining in the $\mathrm{SN}$ was located in puncta indicative of axon terminations. To verify that opsin expression in NAcore neurons produced light-sensitive projections to the $\mathrm{SN}$, additional animals were injected with AAV-ArchT-GFP in the NAcore, and slices of the $\mathrm{SN}$ were made. Figure $2 D$ shows that evoked IPSCs were reduced during laser light delivery $\left(t_{(6)}=3.127, p=0.020\right)$. Figure $2 E$ shows that laser reduced sIPSC frequency $\left(t_{(8)}=2.656, p=0.029\right)$, but not amplitude $\left(t_{(8)}=0.051, p=0.960\right)$, indicating that, as expected, the reduction in evoked IPSC amplitude likely resulted from presynaptic, not postsynaptic, inhibition. In contrast with the indirect pathway projections to the dlVP, Figure $2 F$ shows that optogenetic inhibition of afferents to the $\mathrm{SN}$ did not inhibit reinstated cocaine seeking. Lever-pressing was equivalent and significantly above extinction baseline pressing regardless of whether the rats received light or sham treatments (Friedman statistic, 8.07, $p=0.015, n=7$ ).

\section{Optical inhibition of dIVP and VTA inputs to the NAcore}

The dlVP has a reciprocal GABAergic projection back to the NAcore (Hakan et al., 1992; Groenewegen et al., 1993; Churchill and Kalivas, 1994). To test whether this projection plays a role in reinstatement, we microinjected AAV-ArchT-GFP into the dlVP and placed the optic fibers into the NAcore. Figure $3 A$ shows the self-administration and extinction data for this group of animals. Immune-staining for ArchT-GFP confirmed strong expression at both the dlVP injection site ventral to the anterior commissure (Fig. 3B) and the NAcore terminal field (Fig. 3C). To verify that infection of this pathway produced light-sensitive inhibition of projections to the NAcore, additional animals were pretreated with AAV-ArchT-GFP in the dlVP, and slices of the NAcore were 
made. Figure $3 D$ shows evoked IPSCs were reduced during laser light delivery (Wilcoxon, $p=0.004$ ). Figure $3 E$ shows that laser reduced sIPSC frequency, but not amplitude, indicating that the reduction in evoked IPSC amplitude likely resulted from presynaptic, not postsynaptic, inhibition. Interestingly, of the 10 neurons recorded, 7 showed a laser-induced reduction in SIPSC frequency (Wilcoxon, $p=0.016$ ), while 3 neurons showed a marked increase. The mechanism of this heterogeneity is not clear, but optical inhibition of dlVP GABAergic afferents could have disinhibited either nearby NAcore MSNs that provide lateral inhibition or GABAergic interneurons known to have high spontaneous activity (Pennartz et al., 1994). Regardless of the mechanisms mediating the heterogeneous response, optical inhibition of dlVP projection to the NAcore failed to reduce cocaine-plus-cue-primed reinstatement and rats reinstated above extinction baseline regardless of the sham versus light treatment (Fig. 3F; Friedman statistic, $11.45, p=0.002)$.

Neurons in the VTA project densely to the NAcore (Swanson, 1982 ) and this projection is critical for the rewarding and reinforcing properties of cocaine (Koob and Volkow, 2010). Systemic DA antagonists prevent psychostimulant-induced reinstatement (De Vries et al., 1999), as do localized microinjections of DA receptor antagonists into the NAshell, basolateral amygdala, or PL, but not the NAcore (McFarland and Kalivas, 2001; See et al., 2001; Anderson et al., 2006). Given the apparent lack of necessary involvement by DA in the NAcore in reinstated cocaine seeking, coupled with the emerging appreciation of more heterogeneous neurotransmission from the VTA to NAc that includes glutamate corelease with DA and GABAergic projections (Hnasko et al., 2010; Stuber et al., 2010; Tecuapetla et al., 2010; Brown et al., 2012), we sought to examine inhibition of this pathway to determine its role in reinstatement. Figure $4 A$ shows the selfadministration and extinction training for this group of animals, and Figure $4 B, C$ shows examples of GFP expression from the AAV-ArchT-GFP injection site in the VTA and in fibers in the NAcore, respectively. Figure $4 D$ demonstrates attenuation of cocaine-plus-cue-primed reinstatement by light activation of ArchT to the level of extinction lever-pressing (Friedman statistic, 13.56, $p<0.001)$. In contrast, animals infected with control AAV-GFP showed no effect of light delivery on reinstated cocaine seeking (Fig. $4 D$; Friedman statistic, 9.33, $p=0.006$ ) or an impact of light on cocaine-induced locomotion compared with sham (Fig. $4 E ; t_{(6)}=1.012, p=0.351$ ).

\section{Histology}

Figure 5 shows the location of optical probe termination in each experiment. The area of illumination was estimated to be triangular from the tip of the histologically identified fiberoptic tip and to expand in a cone shape for $\sim 0.5 \mathrm{~mm}$ in length and diameter at the most ventral penetration (Yizhar et al., 2011). Fiber implantations in the ventral pallidum were tightly focused on the dorsal, subcommissural ventral pallidum receiving high-density innervation from the NAcore and largely
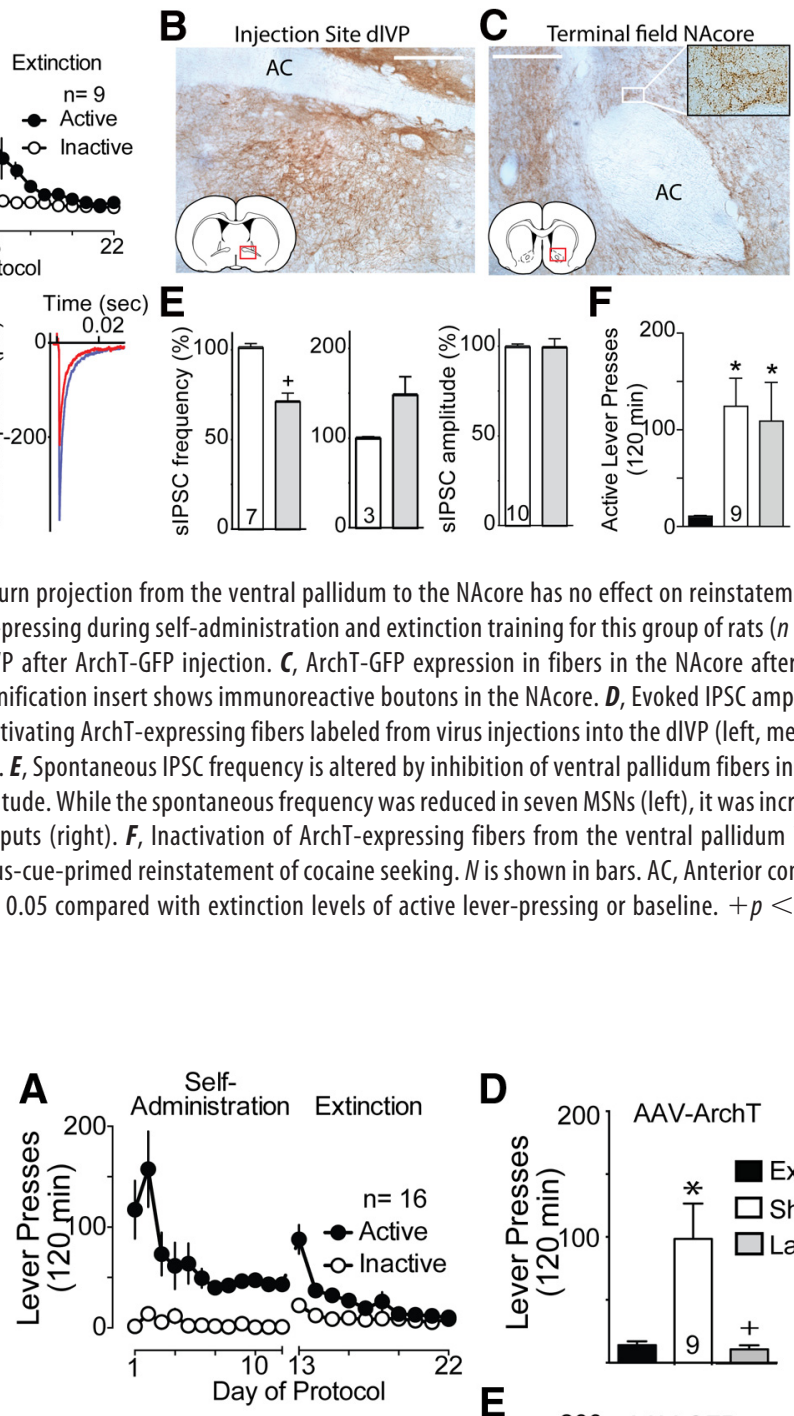

B
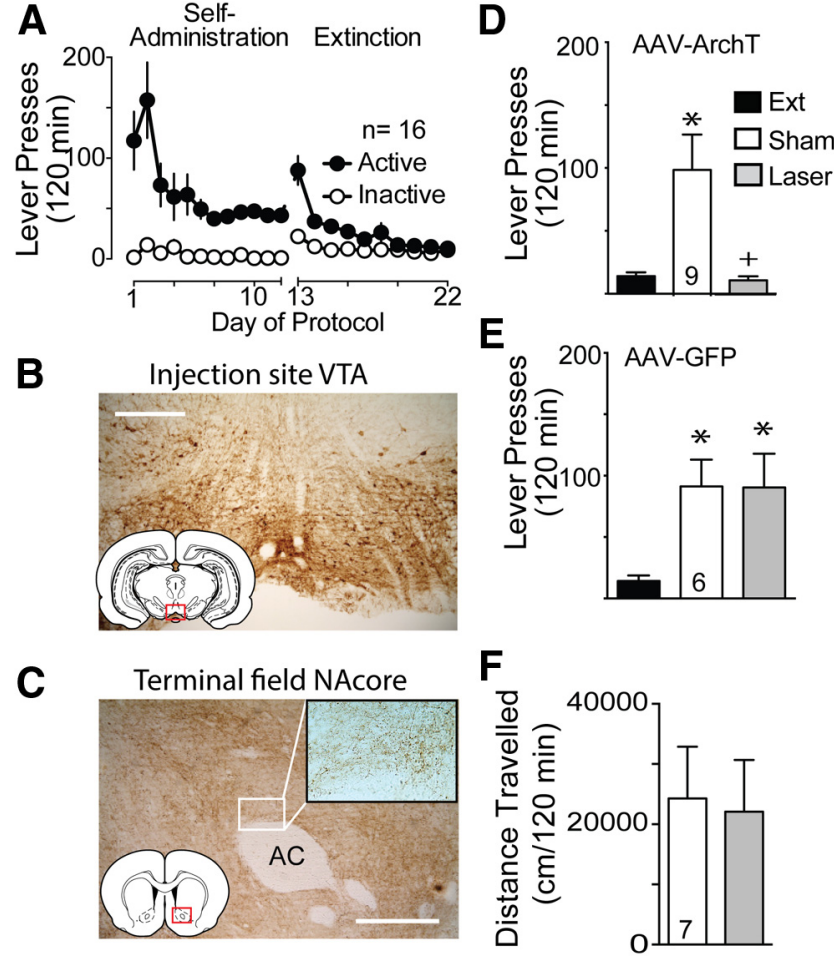

Figure 4. Optical inhibition of VTA terminals in the NAcore prevents cocaine-plus-cueprimed reinstatement. $\boldsymbol{A}$, Active lever-pressing during self-administration and extinction training for this group of rats $(n=16)$. $\boldsymbol{B}$, GFP fluorescence in VTA after ArchT-GFP injection. $\boldsymbol{C}$, ArchT-GFP expression in fibers in the NAcore after virus injection in the VTA. Bouton-like terminations are shown in the high-magnification insert. $D$, Optical stimulation of fibers expressing ArchT prevented reinstated cocaine seeking. $\boldsymbol{E}$, Laser illumination of fibers expressing only GFP was without effect on reinstated cocaine seeking. $\boldsymbol{F}$, Locomotor activity following a cocaine injection was not altered by ArchT activation in the NAcore. $N$ is shown in bars. AC, Anterior commissure. Scale bar, $300 \mu \mathrm{m} .{ }^{*} p<0.05$ compared with extinction levels of active leverpressing. $+p<0.05$ comparing laser and sham treatments. 

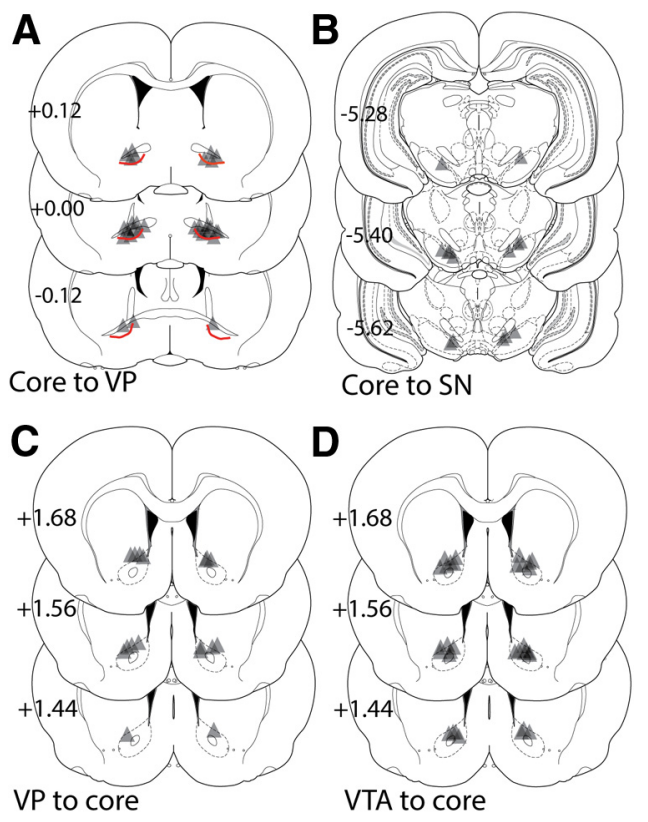

Figure 5. Location of fiber-optic termination in the NAcore, dIVP, and medial SN for each experiment. Triangle shape shows the approximate predicted perimeter of laser light diffusion in the brain. Cone shape expands for $\sim 0.5 \mathrm{~mm}$ in length and $0.5 \mathrm{~mm}$ in diameter from the most ventral penetration of the optic fiber. Accordingly, in Figure 5, the apex of the triangle corresponds with the histologically identified ventral point of the optic fiber and triangle illustrates the approximate shape and size of the illuminated tissue. $\boldsymbol{A}$, Locations of optic fiber in the ventral pallidum (VP) following virus injection into the NAcore (Fig. 1). The thick red line illustrates the division between the dIVP (located dorsal to the line and below the anterior commissure) and the rest of the VP. This line was drawn based on the location of the most dense enkephalin immunoreactivity (Tripathi et al., 2010; Kupchik and Kalivas, 2013) combined with retrograde tracing studies showing the dIVP projects almost entirely through the indirect circuit, while a portion of the neurons in the remainder of the VP project within the direct circuit to the mediodorsal thalamus (Bell et al., 1995; Churchill et al., 1996). B, Locations of fiber-optic termination in the $\mathrm{SN}$ following virus injection into the NAcore from experiment shown in Figure 2. C, Fiber-optic termination in the NAcore following virus injection in the VP, an experiment shown in Figure 3. D, Termination of the optic fiber in the NAcore following ArchT injection in the VTA, as shown in Figure 4. Schematic coronal sections were taken from Paxinos and Watson (2005). The numbers refer to location of the coronal section in millimeters relative to bregma.

lacking neurons projecting to the medial thalamus that could be considered direct pathway projections (Fig. 5A; Smith et al., 2013). Fiber implantations into the ventral mesencephalon focused largely on the border between the medial SN and VTA (Fig. 5B). In the NAcore, fibers were localized to the dorsal half of the nucleus, more frequently in the medial than the lateral quadrant (Fig. 5C,D).

\section{Discussion}

We used a cocaine-plus-cue reinstatement model in rats trained to self-administer cocaine (Shaham et al., 2003) to show that inhibiting fibers in the indirect pathway from the NAcore to the dlVP reduced reinstated cocaine seeking while inhibiting direct pathway projections to the medial $\mathrm{SN}$ was without effect. We also examined two primary afferents to the NAcore, and showed that inhibiting VTA afferents prevented reinstatement, while inhibiting the reciprocal projection back from the dlVP was without effect. Together with findings from our previous optogenetic study using the same relapse model (Stefanik et al., 2013), these data define a circuit that needs to be active to initiate cocaineplus-cue-induced reinstatement of cocaine seeking. Figure 6 shows that this circuit includes NAcore inputs from the PL and

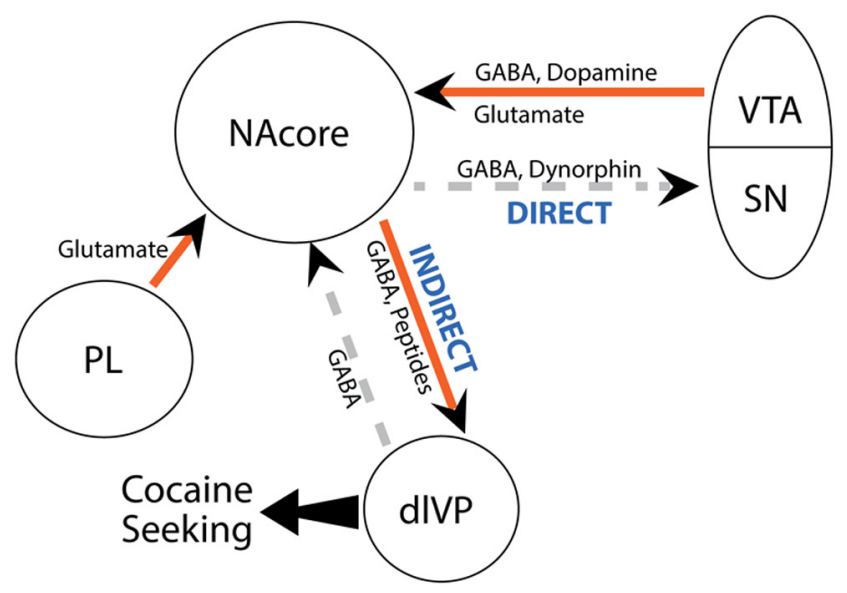

Figure 6. Proposed circuit activated during reinstatement of cocaine seeking. The circuit illustrates the connectivity of regions that have been implicated in the reinstatement of drug seeking. Neurotransmission from the PL (Stefanik et al., 2013) and VTA converge on the NAcore, which sends an indirect pathway projection to the ventral pallidum, initiating drug seeking. In contrast, activity in the direct projections from the NAcore to the SN is not necessary for reinstated cocaine. Arrows indicate the direction of the projection. Red solid arrows indicate projections in which activity is required for cocaine-plus-cue-induced reinstatement, while dashed arrows identify activities that are not necessary for the behavior.

VTA, and efferent projections through the indirect pathway to the dlVP.

\section{Involvement of the direct versus indirect pathways in cocaine reinstatement}

Striatal MSNs are characterized as having efferent projections through the direct pathway to the ventral mesencephalon (VTA and SN) and via the indirect pathway to the pallidum (ventral and globus pallidus; Gerfen and Surmeier, 2011). In the dorsal striatum, contributions to the direct and indirect pathways are almost entirely segregated according to whether the MSNs express D1 or D2 DA receptors (Le Moine and Bloch, 1995; Gerfen and Surmeier, 2011). D1-expressing MSNs project through the direct pathway to the SN, while D2 MSNs project through the indirect pathway to the globus pallidus (Gerfen et al., 1990). However, retrograde, double-labeling studies reveal that while MSNs in the accumbens expressing D2 mRNA project selectively through the indirect pathway to the ventral pallidum, D1-expressing MSNs project heavily through the both indirect and direct pathway to innervate the ventral pallidum, VTA, and medial SN (Lu et al., 1998; Zhou et al., 2003). Thus, diminishing reinstated cocaine seeking by optogenetically inhibiting NAcore indirect projections to the dlVP does not inform whether inhibiting one or both D1-expressing or D2-expressing MSNs is responsible. However, an emerging literature using D1-Cre or D2-Cre transgenic mice or cell-specific viral infection generally shows that activating D1 MSNs potentiates cocaine reward and locomotor sensitization, while activating D2-MSNs reduces cocaine reward and locomotor sensitization (Lobo et al., 2010; Ferguson et al., 2011; Lobo and Nestler, 2011). This conclusion is consistent with a recent study in which selective activation or inhibition of D2-expressing MSNs inhibited or potentiated, respectively, compulsive cocaine self-administration (Bock et al., 2013). Combined with our findings showing a critical role of NAcore projections through the indirect pathway to the dIVP, it seems likely that the accumbensto-dlVP projection may provide a nuanced regulation of reinstated cocaine seeking by both D1-expressing and D2-expressing neurons. A multifaceted equilibrium between D1 and D2 MSN 
NAcore inputs to the dlVP mediating reinstated cocaine seeking is supported by the fact that although D1 and D2 MSNs are GABAergic, they are differentially enriched in neuropeptide cotransmitters that can presynaptically and postsynaptically modulate GABA synaptic transmission (Curran and Watson, 1995; Zahm et al., 1996). The relevance of these cotransmitters to reinstatement is indicated because D2 neurons coexpress preproenkephalin (Curran and Watson, 1995) and $\mu$ opioid receptor inhibition of GABA release in the ventral pallidum is necessary for reinstated cocaine seeking (Tang et al., 2005). Neurotensin is also largely in D2 neurons (Delle Donne et al., 1996), but promotes GABA release in the dlVP and inhibits cue-induced reinstatement, while potentiating cocaine-induced reinstatement (Torregrossa and Kalivas, 2008). Finally, substance P and cocaine-regulated and amphetamine-regulated transcript (CART) are colocalized with GABA in D1 neurons and innervate the ventral pallidum (Hubert and Kuhar, 2005; Commons, 2010). When microinjected into the ventral pallidum, substance $\mathrm{P}$ induces place preference and CART inhibits cocaine-induced locomotion (Commons, 2010; Hubert et al., 2010).

Another level of intricacy is that the ventral pallidum is topographically complex with the rostral and caudal regions that are preferentially filled with neuronal populations having distinct electrophysiological profiles (Kupchik and Kalivas, 2013), and mediating distinct reward-related behaviors (Smith et al., 2009). Finally, it is important to note that while the direct pathway from the NAcore to $\mathrm{SN}$ is not critical for cocaine-plus-cue-induced reinstatement, the role of the NAshell projection to the adjacent VTA is a direct pathway that may be more critically involved since cue-induced reinstatement is correlated with the extent of Fos expression in NAshell MSNs retrogradely labeled from the VTA (Mahler and Aston-Jones, 2012), and in the present study we show that optical inhibition of VTA projections to the NAcore prevents reinstated cocaine seeking.

\section{Involvement of the VTA projections to the NAcore in reinstatement}

The virus used in our experiments (AAV2-CAG-ArchT) codes for a constitutive promoter capable of infecting and expressing ArchT in all neurons within the vicinity of virus delivery. This method allows for robust expression of the opsin at the injection site and the ability to confer specificity of inhibition by the placement of the optic fiber in the corresponding terminal field, limiting inactivation to only fibers expressing ArchT. While we are able to control the inhibition of VTA fibers in the NAcore, this methodology does not allow us to determine precisely which neurotransmitter is driving the observed behavior, which could include DA, glutamate, and/or GABA (Kim et al., 2010; Stuber et al., 2010; Brown et al., 2012; van Zessen et al., 2012).

Given the abundance of data showing that pharmacological inactivation of the VTA prevents reinstated cocaine seeking (Kalivas and Volkow, 2005; Koob and Volkow, 2010), it is not surprising that optically inhibiting the VTA afferents to the NAcore blocked reinstated cocaine seeking. However, previous studies have shown that inhibiting D1 or D2 receptors in the NAcore does not alter reinstated cocaine seeking, while blocking D1 or D2 receptors in the NAshell reduces reinstatement (McFarland and Kalivas, 2001; Anderson et al., 2003, 2006; McFarland et al., 2004). This apparent paradox may be resolved by the fact that the NAcore not only receives dopaminergic, but also GABAergic and glutamatergic projections from the VTA (Kim et al., 2010; Stuber et al., 2010; Brown et al., 2012; van Zessen et al., 2012). The release of glutamate from VTA afferents may be particularly important since blocking AMPA glutamate receptors in the NAcore prevents reinstated cocaine seeking (Kalivas, 2009; Wolf, 2010). Also, operant responding for reward can be promoted or inhibited equally by optogenetically regulating glutamatergic afferents to the NAshell regardless of whether they arise from the hippocampus, amygdala, or PL, indicating that regardless of the source, glutamate release into the accumbens facilitates reward behavior (Britt et al., 2012). Alternatively, a role for inhibiting the GABAergic projection is indicated by the recent demonstration that GABAergic afferents to the nucleus accumbens from the VTA synapse almost exclusively on cholinergic interneurons (Brown et al., 2012). Acetylcholine transmission in the accumbens inhibits cue-induced heroin reinstatement (Zhou et al., 2007). Thus, optogenetically inhibiting the VTA could disinhibit the activity of the cholinergic interneurons and thereby reduce reinstated cocaine seeking.

\section{Technical concerns}

Given that, in addition to axon terminals, optical inhibition is also produced in opsin-infected fibers of passage, it is possible that some D1-expressing axon fibers coursing through the ventromedial ventral pallidum to SN may have been silenced (Groenewegen and Russchen, 1984). However, the lack of effect by directly inhibiting D1-expressing terminations in the medial SN argues that any silencing of these axons of passage is not contributing to the inhibition of reinstated cocaine seeking. Furthermore, the location of optic fiber tips in the dorsal aspect of the dIVP makes less likely significant silencing of the D1-expressing fibers that pass more densely through the ventral pallidum (Heimer et al., 1991).

\section{Conclusions}

Our data show that neuronal activity in the indirect projection from the NAcore to the dIVP is necessary for reinstated cocaine seeking. Since activity in D1-expressing MSNs is necessary for cocaine reward and sensitization (Lobo et al., 2010; Ferguson et al., 2011; Lobo and Nestler, 2011), we were surprised to find that activity in the direct pathway projection to the medial $\mathrm{SN}$ was not necessary, especially since activity in direct pathway projections from the NAshell to the VTA is associated with cocaine reinstatement (McFarland et al., 2004; Mahler and Aston-Jones, 2012). However, a previous pharmacological inactivation study reveals that the VTA likely has a more significant role than the medial SN in regulating cocaine-plus-cue-reinstated cocaine seeking (McFarland and Kalivas, 2001), and we found here that activity in the VTA projection to the NAcore was necessary for reinstatement. Figure 6 shows the movement of information regulating reinstated cocaine seeking from the VTA to NAcore to dlVP. Given the efficacy of optical inhibition in the VTA-to-NAcore pathway to inhibit reinstated cocaine seeking, and the previously reported lack of effect by dopamine antagonists in the NAcore (McFarland and Kalivas, 2001; Anderson et al., 2003, 2006), future studies need to address the relative roles of DA, glutamate, and GABA released from VTA afferents into the NAcore during reinstatement.

\section{References}

Anderson SM, Bari AA, Pierce RC (2003) Administration of the D1-like dopamine receptor antagonist SCH-23390 into the medial nucleus accumbens shell attenuates cocaine priming-induced reinstatement of drug-seeking behavior in rats. Psychopharmacology (Berl) 168:132-138. CrossRef Medline

Anderson SM, Schmidt HD, Pierce RC (2006) Administration of the D2 dopamine receptor antagonist sulpiride into the shell, but not the core, of 
the nucleus accumbens attenuates cocaine priming-induced reinstatement of drug seeking. Neuropsychopharmacology 31:1452-1461. CrossRef Medline

Bell K, Churchill L, Kalivas PW (1995) GABAergic projection from the ventral pallidum and globus pallidus to the subthalamic nucleus. Synapse 20:10-18. CrossRef Medline

Bock R, Shin JH, Kaplan AR, Dobi A, Markey E, Kramer PF, Gremel CM, Christensen CH, Adrover MF, Alvarez VA (2013) Strengthening the accumbal indirect pathway promotes resilience to compulsive cocaine use. Nat Neurosci 16:632-638. CrossRef Medline

Britt JP, Benaliouad F, McDevitt RA, Stuber GD, Wise RA, Bonci A (2012) Synaptic and behavioral profile of multiple glutamatergic inputs to the nucleus accumbens. Neuron 76:790-803. CrossRef Medline

Brown MT, Tan KR, O'Connor EC, Nikonenko I, Muller D, Lüscher C (2012) Ventral tegmental area GABA projections pause accumbal cholinergic interneurons to enhance associative learning. Nature 492: 452-456. CrossRef Medline

Chow BY, Han X, Dobry AS, Qian X, Chuong AS, Li M, Henninger MA, Belfort GM, Lin Y, Monahan PE, Boyden ES (2010) High-performance genetically targetable optical neural silencing by light-driven proton pumps. Nature 463:98-102. CrossRef Medline

Churchill L, Kalivas PW (1994) A topographically organized gammaaminobutyric acid projection from the ventral pallidum to the nucleus accumbens in the rat. J Comp Neurol 345:579-595. CrossRef Medline

Churchill L, Zahm DS, Kalivas PW (1996) The mediodorsal nucleus of the thalamus. I. Forebrain GABAergic innervation. Neuroscience 70:93-102. CrossRef Medline

Commons KG (2010) Neuronal pathways linking substance P to drug addiction and stress. Brain Res 1314:175-182. CrossRef Medline

Curran EJ, Watson SJ Jr (1995) Dopamine receptor mRNA expression patterns by opioid peptide cells in the nucleus accumbens of the rat: a double in situ hybridization study. J Comp Neurol 361:57-76. CrossRef Medline

Delle Donne KT, Sesack SR, Pickel VM (1996) Ultrastructural immunocytochemical localization of neurotensin and the dopamine D2 receptor in the rat nucleus accumbens. J Comp Neurol 371:552-566. CrossRef Medline

De Vries TJ, Schoffelmeer AN, Binnekade R, Vanderschuren LJ (1999) Dopaminergic mechanisms mediating the incentive to seek cocaine and heroin following long-term withdrawal of IV drug self-administration. Psychopharmacology 143:254-260. CrossRef Medline

Ersche KD, Barnes A, Jones PS, Morein-Zamir S, Robbins TW, Bullmore ET (2011) Abnormal structure of frontostriatal brain systems is associated with aspects of impulsivity and compulsivity in cocaine dependence. Brain 134:2013-2024. CrossRef Medline

Ferguson SM, Eskenazi D, Ishikawa M, Wanat MJ, Phillips PE, Dong Y, Roth BL, Neumaier JF (2011) Transient neuronal inhibition reveals opposing roles of indirect and direct pathways in sensitization. Nat Neurosci 14:22-24. CrossRef Medline

Gerfen CR, Surmeier DJ (2011) Modulation of striatal projection systems by dopamine. Annu Rev Neurosci 34:441-466. CrossRef Medline

Gerfen CR, Engber TM, Mahan LC, Susel Z, Chase TN, Monsma FJ Jr, Sibley DR (1990) D1 and D2 dopamine receptor-regulated gene expression of striatonigral and striatopallidal neurons. Science 250:1429-1432. CrossRef Medline

Goldstein RZ, Volkow ND (2011) Dysfunction of the prefrontal cortex in addiction: neuroimaging findings and clinical implications. Nat Rev Neurosci 12:652-669. CrossRef Medline

Groenewegen HJ, Russchen FT (1984) Organization of the efferent projections of the nucleus accumbens to pallidal, hypothalamic, and mesencephalic structures: a tracing and immunohistochemical study in the cat. J Comp Neurol 223:347-367. CrossRef Medline

Groenewegen HJ, Berendse HW, Haber SN (1993) Organization of the output of the ventral striatopallidal system in the rat: ventral pallidal efferents. Neuroscience 57:113-142. CrossRef Medline

Hakan RL, Berg GI, Henriksen SJ (1992) Electrophysiological evidence for reciprocal connectivity between the nucleus accumbens septi and ventral pallidal region. Brain Res 581:344-350. CrossRef Medline

Heimer L, Zahm DS, Churchill L, Kalivas PW, Wohltmann C (1991) Specificity in the projection patterns of accumbal core and shell in the rat. Neuroscience 41:89-125. CrossRef Medline

Hnasko TS, Chuhma N, Zhang H, Goh GY, Sulzer D, Palmiter RD, Rayport S, Edwards RH (2010) Vesicular glutamate transport promotes dopamine storage and glutamate corelease in vivo. Neuron 65:643-656. CrossRef Medline

Hubert GW, Kuhar MJ (2005) Colocalization of CART with substance P but not enkephalin in the rat nucleus accumbens. Brain Res 1050:8-14. CrossRef Medline

Hubert GW, Manvich DF, Kuhar MJ (2010) Cocaine and amphetamineregulated transcript-containing neurons in the nucleus accumbens project to the ventral pallidum in the rat and may inhibit cocaine-induced locomotion. Neuroscience 165:179-187. CrossRef Medline

Huff ML, Miller RL, Deisseroth K, Moorman DE, LaLumiere RT (2013) Posttraining optogenetic manipulations of basolateral amygdala activity modulate consolidation of inhibitory avoidance memory in rats. Proc Natl Acad Sci U S A 110:3597-3602. CrossRef Medline

Kalivas PW (2009) The glutamate homeostasis hypothesis of addiction. Nat Rev Neurosci 10:561-572. CrossRef Medline

Kalivas PW, Volkow ND (2005) The neural basis of addiction: a pathology of motivation and choice. Am J Psychiatry 162:1403-1413. CrossRef Medline

Kim YB, Matthews M, Moghaddam B (2010) Putative gamma-aminobutyric acid neurons in the ventral tegmental area have a similar pattern of plasticity as dopamine neurons during appetitive and aversive learning. Eur J Neurosci 32:1564-1572. CrossRef Medline

Koob GF, Volkow ND (2010) Neurocircuitry of addiction. Neuropsychopharmacology 35:217-238. CrossRef Medline

Kravitz AV, Tye LD, Kreitzer AC (2012) Distinct roles for direct and indirect pathway striatal neurons in reinforcement. Nat Neurosci 15:816-818. CrossRef Medline

Kupchik YM, Kalivas PW (2013) The rostral subcommissural ventral pallidum is a mix of ventral pallidal neurons and neurons from adjacent areas: an electrophysiological study. Brain Struct Funct. Advance online publication. Retrieved July 15, 2013. doi:10.1007/s00429-012-0471-9. CrossRef Medline

LaLumiere RT, Smith KC, Kalivas PW (2012) Neural circuit competition in cocaine-seeking: roles of the infralimbic cortex and nucleus accumbens shell. Eur J Neurosci 35:614-622. CrossRef Medline

Le Moine C, Bloch B (1995) D1 and D2 dopamine receptor gene expression in the rat striatum: sensitive cRNA probes demonstrate prominent segregation of D1 and D2 mRNAs in the distinct neuronal populations of dorsal and ventral striatum. J Comp Neurol 355:418-426. CrossRef Medline

Lobo MK, Nestler EJ (2011) The striatal balancing act in drug addiction: distinct roles of direct and indirect pathway medium spiny neurons. Front Neuroanat 5:41. CrossRef Medline

Lobo MK, Covington HE 3rd, Chaudhury D, Friedman AK, Sun H, DamezWerno D, Dietz DM, Zaman S, Koo JW, Kennedy PJ, Mouzon E, Mogri M, Neve RL, Deisseroth K, Han MH, Nestler EJ (2010) Cell type-specific loss of BDNF signaling mimics optogenetic control of cocaine reward. Science 330:385-390. CrossRef Medline

Lu XY, Ghasemzadeh MB, Kalivas PW (1998) Expression of D1 receptor, $D 2$ receptor, substance $P$ and enkephalin messenger RNAs in the neurons projecting from the nucleus accumbens. Neuroscience 82:767-780. Medline

Lüscher C, Malenka RC (2011) Drug-evoked synaptic plasticity in addiction: from molecular changes to circuit remodeling. Neuron 69:650-663. CrossRef Medline

Mahler SV, Aston-Jones GS (2012) Fos activation of selective afferents to ventral tegmental area during cue-induced reinstatement of cocaine seeking in rats. J Neurosci 32:13309-13326. CrossRef Medline

McFarland K, Kalivas PW (2001) The circuitry mediating cocaine-induced reinstatement of drug-seeking behavior. J Neurosci 21:8655-8663. Medline

McFarland K, Davidge SB, Lapish CC, Kalivas PW (2004) Limbic and motor circuitry underlying footshock-induced reinstatement of cocaine-seeking behavior. J Neurosci 24:1551-1560. CrossRef Medline

Owesson-White CA, Ariansen J, Stuber GD, Cleaveland NA, Cheer JF, Wightman RM, Carelli RM (2009) Neural encoding of cocaine-seeking behavior is coincident with phasic dopamine release in the accumbens core and shell. Eur J Neurosci 30:1117-1127. CrossRef Medline

Paxinos G, Watson C (2005) The rat brain in stereotaxic coordinates, Ed 5. Amsterdam: Elsevier.

Pennartz CM, Groenewegen HJ, Lopes da Silva FH (1994) The nucleus accumbens as a complex of functionally distinct neuronal ensembles: an 
integration of behavioural, electrophysiological and anatomical data. Prog Neurobiol 42:719-761. Medline

See RE, Kruzich PJ, Grimm JW (2001) Dopamine, but not glutamate, receptor blockade in the basolateral amygdala attenuates conditioned reward in a rat model of relapse to cocaine-seeking behavior. Psychopharmacology (Berl) 154:301-310. CrossRef

Shaham Y, Shalev U, Lu L, De Wit H, Stewart J (2003) The reinstatement model of drug relapse: history, methodology and major findings. Psychopharmacology (Berl) 168:3-20. CrossRef

Smith KS, Tindell AJ, Aldridge JW, Berridge KC (2009) Ventral pallidum roles in reward and motivation. Behav Brain Res 196:155-167. CrossRef Medline

Smith RJ, Lobo MK, Spencer S, Kalivas PW (2013) Cocaine-induced adaptations in D1 and D2 accumbens projection neurons (a dichotomy not necessarily synonymous with direct and indirect pathways). Curr Opin Neurobiol pii:S0959-4388(13)00045-7. CrossRef Medline

Sparta DR, Stamatakis AM, Phillips JL, Hovelsø N, van Zessen R, Stuber GD (2012) Construction of implantable optical fibers for long-term optogenetic manipulation of neural circuits. Nat Protoc 7:12-23. CrossRef Medline

Stefanik MT, Moussawi K, Kupchik YM, Smith KC, Miller RL, Huff ML, Deisseroth K, Kalivas PW, LaLumiere RT (2013) Optogenetic inhibition of cocaine seeking in rats. Addict Biol 18:50-53. CrossRef Medline

Stuber GD, Hnasko TS, Britt JP, Edwards RH, Bonci A (2010) Dopaminergic terminals in the nucleus accumbens but not the dorsal striatum corelease glutamate. J Neurosci 30:8229-8233. CrossRef Medline

Swanson LW (1982) The projections of the ventral tegmental area and adjacent regions: a combined fluorescent retrograde tracer and immunofluorescence study in the rat. Brain Res Bull 9:321-353. CrossRef Medline

Tang XC, McFarland K, Cagle S, Kalivas PW (2005) Cocaine-induced reinstatement requires endogenous stimulation of $\mu$-opioid receptors in the ventral pallidum. J Neurosci 25:4512-4520. CrossRef Medline

Tecuapetla F, Patel JC, Xenias H, English D, Tadros I, Shah F, Berlin J, Deisseroth K, Rice ME, Tepper JM, Koos T (2010) Glutamatergic signaling by mesolimbic dopamine neurons in the nucleus accumbens. J Neurosci 30:7105-7110. CrossRef Medline

Torregrossa MM, Kalivas PW (2008) Neurotensin in the ventral pallidum increases extracellular gamma-aminobutyric acid and differentially affects cue- and cocaine-primed reinstatement. J Pharmacol Exp Ther 325: 556-566. CrossRef Medline

Tripathi A, Prensa L, Cebrián C, Mengual E (2010) Axonal branching patterns of nucleus accumbens neurons in the rat. J Comp Neurol 518:4649-4673. CrossRef Medline

Tsunematsu T, Tabuchi S, Tanaka KF, Boyden ES, Tominaga M, Yamanaka A (2013) Long-lasting silencing of orexin/hypocretin neurons using archaerhodopsin induces slow-wave sleep in mice. Behav Brain Res pii: S0166-4328(13)00292-1. CrossRef Medline

van Zessen R, Phillips JL, Budygin EA, Stuber GD (2012) Activation of VTA GABA neurons disrupts reward consumption. Neuron 73:1184-1194. CrossRef Medline

Watabe-Uchida M, Zhu L, Ogawa SK, Vamanrao A, Uchida N (2012) Whole-brain mapping of direct inputs to midbrain dopamine neurons. Neuron 74:858-873. CrossRef Medline

Wolf ME (2010) The Bermuda Triangle of cocaine-induced neuroadaptations. Trends Neurosci 33:391-398. CrossRef Medline

Yizhar O, Fenno LE, Davidson TJ, Mogri M, Deisseroth K (2011) Optogenetics in neural systems. Neuron 71:9-34. CrossRef Medline

Zahm DS (1989) The ventral striatopallidal parts of the basal ganglia in the rat. II. Compartmentation of ventral pallidal efferents. Neuroscience 30: 33-50. CrossRef Medline

Zahm DS, Heimer L (1993) The efferent projections of the rostral pole of the nucleus accumbens in the rat: comparison with the core and shell projection patterns. J Comp Neurol 327:220-232. CrossRef Medline

Zahm DS, Williams E, Wohltmann C (1996) Ventral striatopallidothalamic projection: IV. Relative involvements of neurochemically distinct subterritories in the ventral pallidum and adjacent parts of the rostroventral forebrain. J Comp Neurol 364:340-362. CrossRef Medline

Zhou L, Furuta T, Kaneko T (2003) Chemical organization of projection neurons in the rat accumbens nucleus and olfactory tubercle. Neuroscience 120:783-798. CrossRef Medline

Zhou W, Liu H, Zhang F, Tang S, Zhu H, Lai M, Kalivas PW (2007) Role of acetylcholine transmission in nucleus accumbens and ventral tegmental area in heroin-seeking induced by conditioned cues. Neuroscience 144: 1209-1218. CrossRef Medline 